\title{
Pluralism in grassland management promotes butterfly diversity in a large Central European conservation area
}

\author{
Konrad Fiedler $^{1} \cdot$ Thomas Wrbka $^{1} \cdot$ Stefan Dullinger $^{1} \mathbb{D}$
}

Received: 16 September 2016 / Accepted: 25 March 2017 / Published online: 8 April 2017

(C) The Author(s) 2017. This article is an open access publication

\begin{abstract}
Extensively harvested grassland ecosystems contribute substantially to European biodiversity, but different kinds of grassland usage may selectively foster individual taxa. A combination of management options may offer a promising way to maximize biodiversity at the landscape scale. Here, we test this hypothesis based on 91 butterfly samples taken in the years 2013-2015 in differently managed areas within a large conservation area, the National Park Neusiedler See/Seewinkel in eastern-most Austria. Altogether, we recorded 4713 butterfly individuals of 35 species. Based on these records, we show that the parallelism of three management options, i.e. pasturing by mobile cattle herds, annual hay cut in early summer, and fallow land mulched in late summer, increase species diversity of butterflies and burnet moths in the regional metacommunity. Even though spatial distances between our sample sites were small compared to the activity ranges of adult butterflies, we found that species composition of butterfly and burnet assemblages significantly differed between the three management options, indicating that assemblages were shaped by factors at the site level. Differences in species composition were stable across three consecutive years, even though there was annual variation in butterfly assemblages. Other tested co-variables (soil moisture, soil nitrogen, abundance of nectar flowers and local plant species richness) did not additionally contribute
\end{abstract}

Electronic supplementary material The online version of this article (doi:10.1007/s10841-017-9974-2) contains supplementary material, which is available to authorized users.

Stefan Dullinger

stefan.dullinger@univie.ac.at

1 Department of Botany \& Biodiversity Research, University of Vienna, Rennweg 14, 1030 Vienna, Austria to explaining species composition of butterfly communities. We conclude that maintaining a combination of three complementary management options is indeed a relevant strategy for biodiversity preservation in this internationally renowned conservation area.

Keywords Biodiversity · Butterflies · Conservation · Management $\cdot$ Semi-natural grassland $\cdot$ Vegetation . Species composition

\section{Introduction}

The 'semi-natural' grasslands of temperate Europe are the result of a long history of human land use (Ellenberg 2009). Traditional low-intensity grazing and hay making have generated ecosystems that often are species-rich (e.g. Pykälä et al. 2005). Moreover, the existence of grassland ecosystems augments regional meta-communities by specialists of open habitats and thereby contributes to landscape-level biodiversity (e.g. Botham et al. 2015). Although anthropogenic in origin, these systems are hence of high value for biodiversity conservation (Plieninger et al. 2006). Fostering their maintenance is a goal of European agri-environmental policies (Dover et al. 2011) and a frequent focus of management plans in national parks and other kinds of nature reserves (Öckinger et al. 2006).

While the importance of semi-natural grasslands for biological conservation in Europe is undebated, the 'optimal' management to optimize positive effects on biodiversity is less evident. Actually, different taxonomic groups may respond to different land use types or changing land use intensities in idiosyncratic ways. For example, plant diversity may be maximized under higher grazing intensities than insect diversity (Pöyry et al. 2004, 2006; van 
Klink et al. 2015), and among arthropods optimal intensities may also differ (Sjödin et al. 2008). Switching from grazing to mowing, or to other types of surrogate usage, may either have beneficial (Socher et al. 2013), detrimental (Catorci et al. 2014) or neutral (e.g. Saarinen and Jantunen 2005) effects on the diversity of individual groups. For some groups, even intermediate stages of secondary succession after abandonment may represent the optimal type of 'usage' (Balmer and Erhardt 2000). These differences depend on how the disturbances associated with particular land use regimes interfere with the habitat and resource requirements of particular groups (e.g. Kruess and Tscharntke 2002; van Klink et al. 2015). As a corollary, the 'optimal' management appears highly group-specific, and for conserving cross-taxonomic species richness, diversifying management regimes has hence repeatedly been recommended (e.g. Baur et al. 2006; Berg et al. 2011; Sjödin et al. 2008).

When focussing on one particular taxonomic group in one particular landscape, the management regime that maximizes species richness might, however, more easily be determined. For butterflies, most studies conducted so far suggested that species richness might peak under low intensity grazing or even after cessation of grazing (Balmer and Erhardt 2000; Kruess and Tscharntke 2002; Baur et al. 2006). The negative effects of higher grazing intensities most probably arise from unintentional predation and decreased resource abundance (=biomass of plants, van Klink et al. 2015) as well as from structural homogenization of the vegetation sward (Jerrentrup et al. 2014). On the other hand, shrub and tree encroachment have highly negative effects on butterfly diversity (Öckinger et al. 2006; Marini et al. 2008; Bubová et al. 2015). To maintain grasslands and simultaneously avoid negative grazing effects, mowing has been suggested as an optimal management regime for butterfly conservation (Bubová et al. 2015). However, studies comparing mown and grazed grasslands on butterfly species richness revealed equivocal results (e.g. Saarinen and Jantunen 2005; D'Aniello et al. 2011). These partly contradictory findings may result from differences in mowing dates and frequencies or from variation in the response of individual butterfly species to different management regimes (Berg et al. 2011; Bubová et al. 2015). One might hence assume that, like in the case of crosstaxon diversity, the best way to maximize butterfly species richness in a large grassland ecosystem should be a diversification of management regimes (Botham et al. 2015). On the other hand, given the high mobility of adult butterflies and their usually opportunistic resource use when nectaring, one might expect that segregation of local assemblages within a mosaic landscape of e.g. meadows and pastures will hardly be detectable. The idea that mixing different grassland management regimes within one landscape-scale nature reserve could actually foster butterfly diversity remains, hence, to be tested.

The National Park Neusiedler See/Seewinkel in easternmost Austria offers a suitable system to study the effect of diversified grassland usage on butterfly species composition and diversity. Three management regimes, i.e. extensive grazing by free-ranging cattle, low-intensity hay harvest (one cut in early summer) and grassland-like fallows (kept free of shrubs and trees by annual mowing in late summer, yet without biomass removal) coexist, often in small-scale mosaics, in this area as a consequence of the region's land use history. In the present study, we ask whether local butterfly assemblages actually segregate between these management types and whether such differences can be traced even in data assembled in short (and hence necessarily incomplete) surveys, as they are often performed during rapid biodiversity assessments. In addition, we analyse differences in plant community composition among management types and evaluate if certain ecological characteristics of these plant communities contribute to explaining possible differences in butterfly assemblages. Taken together, our study aims at testing if a diversified grassland usage contributes to fostering overall butterfly diversity at the landscape level.

\section{Materials and methods}

\section{Study system}

The National Park Neusiedler See/Seewinkel in easternmost Austria is situated in a transition zone between oceanic and continental climate. The natural forest cover of the area (mainly different species of oak, Quercus spp.) has been gradually replaced by grasslands as result of livestock husbandry since medieval times (Wendelberger 1959). For centuries, herds of cattle, in particular, ranged over large areas during the growing season. In parallel, a fraction of land was always managed by mowing to obtain winter fodder for these animals. By the 1960s, this traditional landuse system became disrupted, and many former pasture areas were converted into arable land, especially vineyards. Since the mid-1980s, pasturing was re-established as a means of ecological restoration (Korner et al. 2008) while at the same time economic development led to the abandonment of many former vineyards. Finally, in the early 1990s the National Park was formally established to protect Lake Neusiedl, its riparian reed ecosystems and the surrounding semi-natural landscape of grasslands ('puszta') and small salt water lakes.

This development has lead to the co-existence of three major types of grasslands in the conservation area which are defined by their different management regimes. First, 
pastures are grazed from April to October by herds of cattle. Animals are not kept in enclosures, but rather range, under control of herdsmen, across the area, thereby exerting an extensive, yet spatially uneven grazing pressure (c. 0.5-1.3 livestock units, Korner et al. 2008). Second, some areas are mown once in early summer (rarely twice in early and late summer) to harvest hay. Third, a sizeable fraction of fallow land (i.e. former vineyards) exists which is also usually mown once a year to prevent secondary succession towards woody vegetation. In contrast to meadows, mowing is postponed to late summer, and the mown biomass is not removed.

\section{Study sites}

The study was conducted in the Seewinkel area east of Lake Neusiedl, in a radius of $5 \mathrm{~km}$ around the village of Illmitz $\left(47^{\circ} 46^{\prime} \mathrm{N}, 16^{\circ} 48^{\prime} \mathrm{E}, 110-120 \mathrm{~m}\right.$ a.s.l.). Based on a land use map of the area (cf. Fig. 1), we randomly pre-selected 15 candidate sampling sites of $50 \times 50 \mathrm{~m}$ from each of the three land use types of pastures, meadows and fallows in

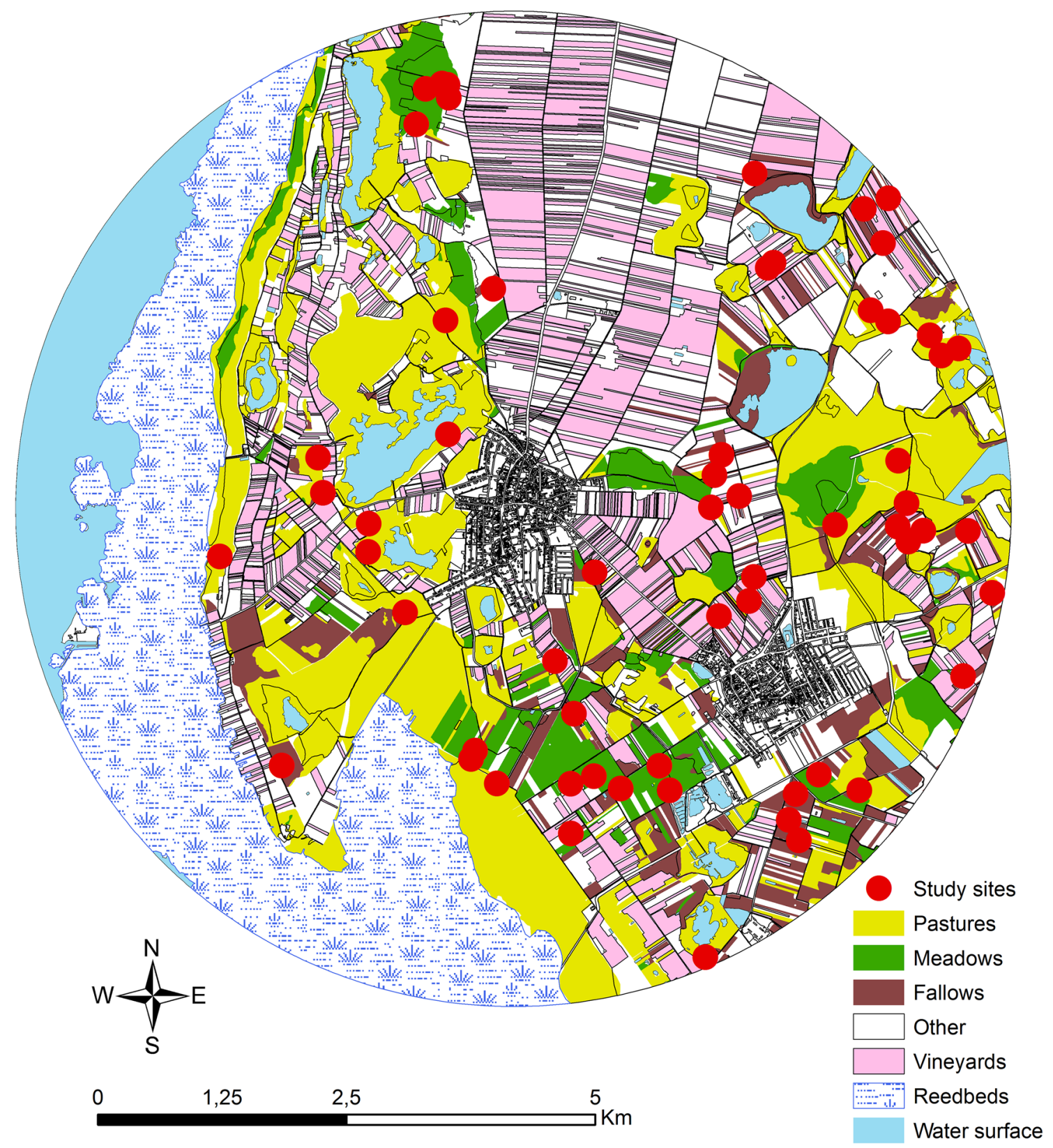

Fig. 1 Map of the study area east of Lake Neusiedl, Austria, centred around the village of Illmitz. Red dots indicate sampling sites that have been surveyed at least once during the years 2013, 2014, and
2015. 'Other' land use types mainly include arable land, settlements and gardens. (Color figure online) 
spring 2013. From this pool, 9-11 sites per land-use type and year were actually visited during 1 week in June 2013 (17/06-21/06), 2014 (22-27/06) and 2015 (08/06-12/06), respectively. We pre-selected a larger pool of candidate sites to guarantee that ten sites per year and land-use type could actually be sampled, i.e. were neither already mown nor actually grazed by cattle herds nor flooded during our survey week. In some cases, however, even the 15 candidate sites were too few to allow for a sample of ten sites. In such cases, we shifted the pre-selected sampling site by 50-250 m within a contiguous area of the same land use type. The final sample contained 91 sites with 11,10 and 10 fallows, 11,9 , and 11 pastures and 9, 9, and 11 meadows in the years 2013, 2014 and 2015, respectively.

\section{Plant surveys}

At each site and in each year, a square of $50 \times 50 \mathrm{~m}^{2}$ was transiently marked and four subplots, each $2 \times 5 \mathrm{~m}^{2}$, were positioned at a distance of $10 \mathrm{~m}$ from the outer margins of this quadrat. All vascular plant species present in these subareas were recorded and their cover estimated on a 7-level ordinal scale (Braun-Blanquet 1964): $<1,1-2,2-5,5-25$, 25-50, 50-75, $<75 \%$. Species determination followed Fischer et al. (2008). Care was taken to place quadrats into areas of homogeneous land use. Where this was not possible because strips of parcels were too narrow the four subareas were positioned in a line with $10 \mathrm{~m}$ distance among each other.

\section{Butterfly surveys}

The same squares of $50 \times 50 \mathrm{~m}^{2}$ were intensively walked by five observers in wavy lines for $10 \mathrm{~min}$ (Kadlec et al. 2012). All encountered butterflies, burnet moths and individuals of the diurnal hawkmoth Macroglossum stellatarum were noted. If necessary for identification, butterflies were captured with a net, identified using Stettmer et al. (2007) or Naumann et al. (1999), and released on the spot after the end of a survey. Care was taken to avoid multiple counts of the same individuals as far as possible. The species pairs Zygaena purpuralis/minos and Colias hyalelalfacariensis were treated as one operational taxonomic unit each, since reliable identification of living specimens in the field is not possible. During all butterfly surveys, the local abundance of nectar flowers was assessed on a rank scale (from 0absent to 5-excellent).

\section{Statistical data analysis}

Plant records from the subplots at each site were combined into one list using mean cover of each species in the subplots as a proxy of abundance. The resulting species $\times$ site matrix was transformed into a triangular Bray-Curtis similarity matrix. A permutational analysis of variance (PERMANOVA, 999 permutations) was then run to test whether plant species composition varied according to management type and survey year as fixed factors and and site (nested within management type) as random factor. Plant species were additionally classified according to their nitrogen and soil water requirements using the indicator value system of Ellenberg et al. (1991) complemented by our own estimates for 14 eastern European species. Indicator values represent an ordinal classification of plants according to the position of their realized ecological niche along these (and other) environmental gradients. Although such indicator values are based on expert judgement and refer to the species' niche optimum only, they have been proven reliable and useful indicators of local-scale environmental conditions in many studies (e.g. Diekmann 2003; Lenoir et al. 2013). From the lists of species and their associated indicator values we then calculated an unweighted mean nitrogen and humidity value for each site. These co-variates were standardized to a mean of zero and a variance of one prior to analysis. This PERMANOVA approach with a combination of fixed (categorical and metric) predictors plus one random factor is analogous to a conventional GLMM, but allows the use of a non-Euclidean similarity matrix as response variable. To visualize influences of habitat characteristics on plant species composition, we performed a constrained ordination, i.e. distance-based redundancy analysis (dbRDA).

Butterfly sight records were square-root transformed to alleviate the prevalence of a few very common species. Then, the species $\times$ site matrix was transformed into a triangular Bray-Curtis similarity matrix after adding a virtual dummy species with one sight record for each site. This procedure has been shown to substantially stabilize ordination results in the case of sparsely populated survey matrices: Clarke et al. 2006). We then ran a permutational analysis of variance (PERMANOVA, 999 permutations) to test whether butterfly species composition varied according to management type and survey year as fixed factors and study site (nested within management type) as random factor. As co-variates we included mean Ellenberg values for soil nitrogen and humidity, as well as vascular plant species richness and nectar flower abundance. All co-variates were scaled to a mean of zero and a variance of one. To visualize influences of habitat descriptors on butterfly community composition, we performed a constrained ordination, i.e. distance-based redundancy analysis (dbRDA). All multivariate community analyses were performed in the PERMANOVA + for PRIMER7 package (Anderson et al. 2008).

Having established the existence of assemblage differences between butterflies associated with the three land-use 
types, we explored whether certain butterfly species may serve as indicators of the respective land-use types using the 'indval' procedure of Dufrene and Legendre (1997) as implemented in Roberts (2016). Finally, we tested whether the beta component of species diversity between the three land-use types contributes to significantly augmenting butterfly diversity at the landscape level, using an additive partitioning approach of the Shannon diversity index ('adipart' implemented in the 'vegan' package: Oksanen et al. 2016). Indicator species analysis and diversity partitioning were performed in R 3.1.1 (R Core Team 2014).

\section{Results}

\section{Plant species composition}

During our surveys we altogether observed 302 vascular plant species (mean \pm SD per site and year: $36.60 \pm 12.18$, range 8-73 species; see Table S1, Electronic Supplement). Species composition varied strongly between the three management types, but distinctly less so between years and between sites within each management type (Table 1). In addition, the Ellenberg index values for humidity significantly varied among the local plant assemblages of the three management types whereas soil nitrogen did not capture a significant additional fraction of variance. Overall, these site descriptors explained about $38.6 \%$ of the variance in plant species composition in a dbRDA model.

The ordination plot (Fig. 2) reveals that pasture and, in particular, fallow sites formed two rather compact, well segregated clusters with regard to their vascular plant species composition. Meadow sites, in contrast, varied more strongly among each other. Among meadow and pasture sites, species composition varied with soil humidity. All fallows, but also some of the meadows, were associated

Table 1 Results of a mixed-model PERMANOVA on plant species composition on 91 grassland sites (quantified as Bray-Curtis similarity distance matrix) relative to management type, survey year, soil humidity and soil nitrogen

\begin{tabular}{lrrrll}
\hline Source & df & \multicolumn{1}{l}{ SS } & \multicolumn{1}{l}{ MS } & $F$ & $P$ \\
\hline Management & 2 & 63410.0 & 31705.0 & $\mathbf{8 . 9 4 6}$ & $\mathbf{0 . 0 0 1}$ \\
Year & 2 & 9201.5 & 4600.8 & $\mathbf{2 . 0 6 6}$ & $\mathbf{0 . 0 0 3}$ \\
Management × year & 4 & 11369.0 & 2842.2 & 1.273 & 0.094 \\
Site (Management) & 63 & 179200.0 & 2844.4 & $\mathbf{1 . 8 2 4}$ & $\mathbf{0 . 0 0 1}$ \\
Soil humidity & 1 & 3557.2 & 3557.2 & $\mathbf{2 . 2 8 2}$ & $\mathbf{0 . 0 1 6}$ \\
Soil nitrogen & 1 & 1756.0 & 1756.0 & 1.126 & 0.357 \\
Residuals & 17 & 26504.0 & 1559.1 & & \\
Total & 90 & 294990.0 & & & \\
\hline
\end{tabular}

$S S$ sum of squares, $M S$ mean squares

Significant factors $(P<0.05)$ highlighted in bold face

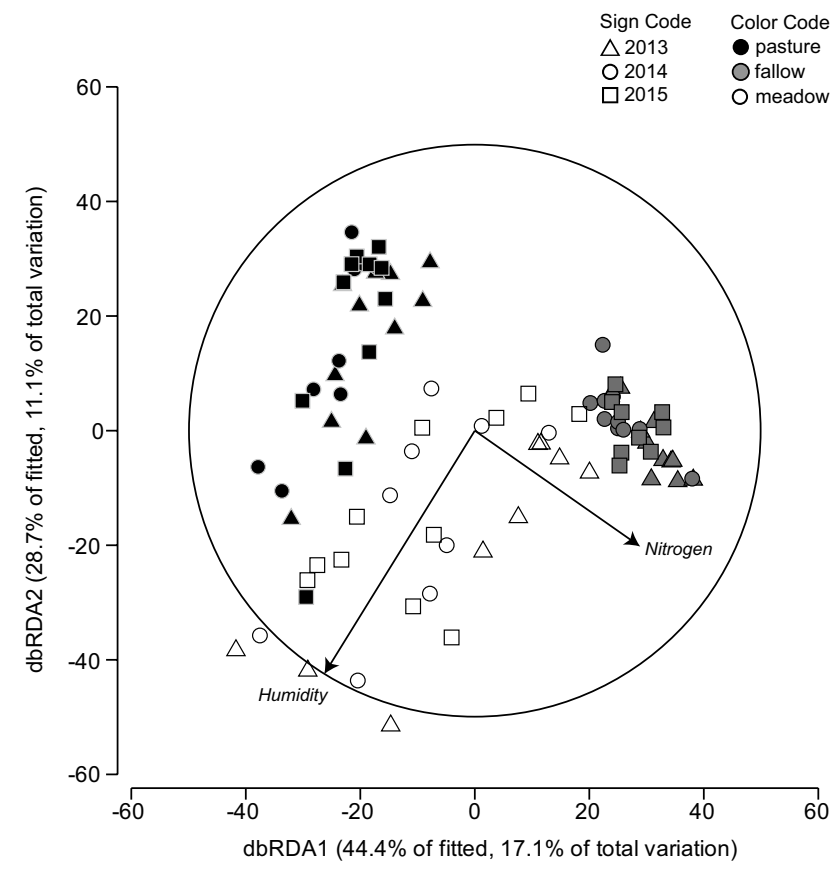

Fig. 2 Constrained ordination plot (dbRDA) of plant assemblages at 91 grassland sites. Open-meadows; black-pastures; grey-fallows. Triangles - 2013, dots-2014, squares-2015. Vectors indicate correlations between ordination axes and the mean Ellenberg values for soil nitrogen and humidity

with moderately high levels of nitrogen supply. Interannual differences, despite being statistically significant in the PERMANOVA model, did not become obvious along the first two ordination axes.

\section{Butterfly species composition}

We observed a total of 35 butterfly and burnet species (mean \pm SD per site and year: $6.37 \pm 2.53$, range $1-13$ species, represented through 4713 individual sightings; see Table S2, Electronic Supplement). Butterfly species composition differed more strongly between survey years than according to management type, but these two factors clearly attained the highest explanatory power of all tested factors (Table 2). There was no significant management $x$ year interaction. Soil humidity, soil nitrogen, nectar flower abundance and plant species richness of a site did not influence local butterfly assemblage composition significantly. Overall, the factors included in the dbRDA model explained $37.6 \%$ of the variance in butterfly species composition.

Butterfly communities observed in 2014 (with consistently higher values along the first ordination axis, Fig. 3) differed distinctly from those in the two other years. Within the surveys of each year, pasture sites tended to harbour butterfly communities quite different from those seen 
Table 2 Results of a mixed-model PERMANOVA of butterfly species composition on 91 grassland sites (quantified as Bray-Curtis similarity matrix) relative to management type, survey year, soil humidity, soil nitrogen, plant species richness and nectar flower abundance

\begin{tabular}{lrrrrl}
\hline Source & df & \multicolumn{1}{l}{ SS } & \multicolumn{1}{l}{ MS } & \multicolumn{1}{l}{$P$} \\
\hline Management & 2 & 13835.0 & 6917.4 & 4.704 & $\mathbf{0 . 0 0 1}$ \\
Year & 2 & 28904.0 & 14452.0 & 12.772 & $\mathbf{0 . 0 0 1}$ \\
Management $\times$ year & 4 & 2886.2 & 721.5 & 0.637 & 0.872 \\
Site (Management) & 62 & 75431.0 & 1216.6 & 1.164 & 0.177 \\
Soil humidity & 1 & 409.5 & 409.5 & 0.392 & 0.836 \\
Soil nitrogen & 1 & 770.5 & 770.5 & 0.737 & 0.546 \\
Nectar flower abundance & 1 & 1489.5 & 1489.5 & 1.425 & 0.218 \\
Plant species richness & 1 & 1831.0 & 1831.0 & 1.752 & 0.143 \\
Residuals & 16 & 16725.0 & 1045.3 & & \\
Total & 90 & 142280.0 & & & \\
\hline
\end{tabular}

$S S$ sum of squares, $M S$ mean squares

Significant factors $(P<0.05)$ highlighted in bold face

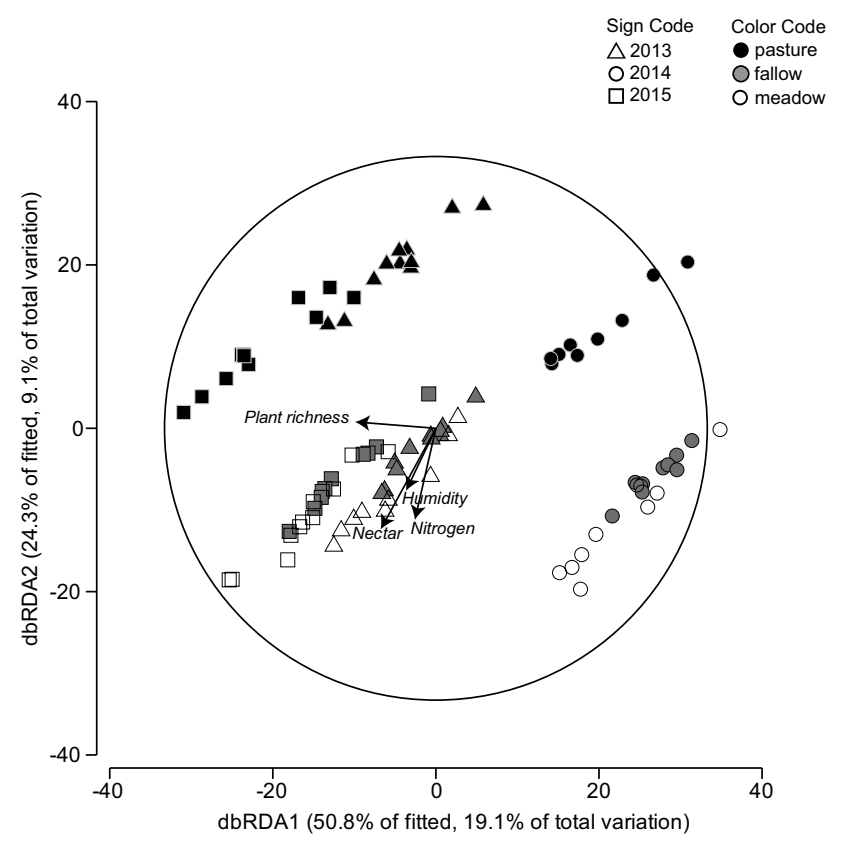

Fig. 3 Constrained ordination plot (dbRDA) of butterfly communities at 91 grassland sites. Open-meadows; black-pastures; greyfallows. Triangles - 2013, dots-2014, squares-2015. Vectors indicate correlations between descriptors of the vegetation at the sites and the two ordination axes

on meadows and fallows, while these latter types did not clearly segregate. Butterfly assemblages on meadows and fallows tended to be associated with more humid, and those of pasture sites with more dry, site conditions, as indicated by Ellenberg values of the respective vegetation. As indicated by the PERMANOVA and dbRDA results, however, further differentiation of butterfly assemblages along the gradients of soil conditions was weak and statistically not significant. Similarly, neither nectar flower abundance nor plant species richness were significantly associated with butterfly species composition at the site level. Nectar flower abundance itself did not vary between management types (one-way ANOVA; $F_{2 ; 88}=0.909, P>0.40$ ) or study years $\left(F_{2 ; 78}=0.0001, \mathrm{P}=0.99\right.$; year $\times$ land-use interaction: $F_{4: 82}=1.206, \mathrm{P}=0.32$ ).

Differentiation of butterfly communities between the three management types also became apparent in the indicator value analysis. At least one butterfly or burnet species showed a characteristic preference of each land-use type (Table 3). Fallows had only one characteristic species, i.e. Cupido argiades.

Diversity partitioning further corroborated that the variety of grassland management types contributed to butterfly species diversity at the landscape-level. Although the beta component is low in absolute terms (observed beta $=0.012$, c. $1.5 \%$ of total diversity) because of the strong effect that some widespread dominant species (e.g. Coenonympha pamphilus, Melanargia galathea, cf. Table S2) have on the statistic (Crist et al. 2003), it is highly significantly larger $(z=13.6, P<0.001)$ than the beta-component expected from randomisation (expected beta $=0.0003$ ).

\section{Discussion}

In the large conservation area NP Neusiedlersee/Seewinkel grassland ecosystems are represented by three major management types. As expected, these types differed markedly with regard to their plant species composition, even if differences in soil humidity and nutrient supply were accounted for in a joint analysis. The segregating effect of grazing versus mowing, respectively, on plant species is well-known and mainly results from differential levels of selectivity and spatial heterogeneity of the two management regimes (e.g. Schlapfer et al. 1998; Rudmann-Maurer et al. 2008; Ellenberg 2009). In our study, there are, for example, a number of dwarf shrubs (e.g. Ononis spinosa, Artemisia santonicum, Thymus kosteleckyanus) or herbs (e.g. Eryngium campestre) which are protected against cattle grazing by spines or secondary metabolites and hence thrive on pastures but are sensitive to mowing. In addition, gap creation by trampling creates colonization opportunities for low growing, partly annual herbs and graminoids (e.g. Carex stenophylla, Cerastium pumilum, Potentilla pusilla) that are competitively excluded from meadows. The weak inter-annual variation in species composition in our data likely results from differences among annual subsets of sampling sites and the exact positioning of the subplots but maybe also from some real turn-over triggered by such small-scale disturbances in pastures, in particular. Fallows, finally, differ in their species composition 
Table 3 Results of the indicator value analysis for butterflies and burnet moths across the three grassland management types

\begin{tabular}{llll}
\hline Species & Land-use type & Indicator value & Probability \\
\hline Cupido argiades & Fallow & 0.1860 & 0.020 \\
Melanargia galathea & Meadow & 0.5140 & 0.001 \\
Maniola jurtina & Meadow & 0.4371 & 0.022 \\
Zygaena carniolica & Pasture & 0.2720 & 0.004 \\
Zygaena & Pasture & 0.1815 & 0.009 \\
purpuralis/minos & & & \\
\hline
\end{tabular}

All species that attained a significant preference value $(P<0.05)$ for one land use type are listed

from meadows because they all originated from arable land (mostly vineyards) within the last $c$. 10-20 years and still contain a lot of species indicative of this origin (e.g. Papaver rhoeas, Anthemis arvensis, Apera spica-venti, cf. Mucina et al. 1994). In the long run, the species composition of these fallows will probably converge with those of the drier meadows although the timing of cut in late summer will probably have a lasting segregative effect (e.g. Ellenberg 2009).

Despite the high mobility of butterflies in a landscape largely devoid of forest barriers, and despite the highly intermingled mosaic-like landscape configuration, butterfly assemblages also demonstrated strong signatures of the local management regimes. Butterfly assemblages on pasture sites, in particular, had a species composition that differed from those seen on meadows and fallows (significantly so in pair-wise post-hoc comparisons in two of three study years). The latter two land-use types harboured more similar butterfly assemblages, which did not differ significantly from another in pair-wise PERMANOVA comparisons within each year (data not shown). The fact that five out of 35 species were identified as 'management indicators' and that land use type was associated with a highly significant beta-diversity component further emphasize that a mixed management regime has a diversifying effect on the regional butterfly metacommunity. Overall, and despite the substantial overlap in butterfly species composition between meadows and fallows, all of these land-use types are hence valuable in terms of increasing butterfly gamma diversity.

The local vegetation might promote local-scale differentiation of butterfly assemblages via selective effects either on the adults or the caterpillars. First, adult butterflies require floral nectar for their energy income. Nectar availability has frequently been shown to be a major driver of butterfly abundance and richness (e.g. Loertscher et al. 1995; Lebeau et al. 2016). In our data set, nectar flower abundance was highly significantly related to the number of butterfly sightings $(\mathrm{r}=0.3957, P<0.001)$. When searching for food, butterflies encounter varying amounts and qualities of resources in the landscape, and this resource availability further fluctuates temporally as a result of management-driven disturbance regimes. Mowing will sporadically remove nearly all nectar sources from meadows as well as from fallows (Bruppacher et al. 2016), but prior to mowing flower densities can be very high. In contrast, under low-intensity grazing nectar supply will be lower but temporally more constant. However, nectar flower availability did not vary consistently between management types in our surveys-which were conducted before the first meadow cut in each year. Therefore, the availability of nectar resources, while an important driver of butterfly activity density at the individual site or survey level, cannot be responsible for the compositional differentiation of butterfly assemblages between the three grassland management types in our study system.

Second, the selective effect of management on plant species composition may have an impact on butterfly assemblages via the host specificity of their caterpillars (e.g. Bink 1992). Indeed, the host plants of the two burnet moth species indicative of pasture sites include plants that are favoured by grazing as opposed to mowing (Eryngium campestre, Pimpinella saxifraga and Thymus species as larval hosts to Zygaena minos and Z. purpuralis, respectively; Onobrychis viciifolia for Z. carniolica). We therefore conclude that varied plant species composition and its selective effects on butterfly larvae is probably the major functional link between grassland management and butterfly species composition in our study region.

The year of study had an even larger influence on butterfly species composition than grassland management. This finding simply reflects variation in annual phenology of butterfly assemblages. Each year, our field surveys were performed during 1 week in June, but the exact week varied among years. In 2014, surveys were conducted at the end of June. Accordingly, species characteristic of the peak summer aspect in Central Europe (such as Maniola jurtina or Melanargia galathea) strongly dominated the samples, whereas the first generations of multivoltine species like Coenonympha pamphilus or Polyommatus icarus were rarely encountered. The opposite was true for the years 2013 and 2015, when surveys were done in the 1st and 2nd week of June, respectively. However, the absence of a statistically significant interaction between survey year and management type with regard to butterfly species composition indicates that these phenological shifts did neither obscure, nor inflate, the management-driven differences in species composition. Nectar flower abundance did not vary between study years, and can therefore not have been responsible for inter-annual differences.

It is worth emphasizing that the differences in butterfly species composition could be extracted from data that do not represent the entire communities because 
they were assembled over just 1 week per year, with survey duration of individual sites as low as $15 \mathrm{~min}$. Usually, butterfly monitoring programs include several replicate surveys within one vegetation period (van Swaay et al. 2008; Kadlec et al. 2012; Fies et al. 2016) instead of yearly replicates during the same season. As indicated by the highly significant effect of 'year' on species composition, variation of the exact week of sampling between early and late June increased the overall coverage of species on the wing during consecutive times of the year and hence partly compensated for the lack of repetition within years. However, early spring and late summer species are certainly missing in our records. Especially at the pasture sites, a number of additional characteristic species would have probably been observed if sampling had been further extended in time (e.g., Nymphalidae: Minois dryas; Lycaenidae: Callophrys rubi, Glaucopsyche alexis, Polyommatus thersites, P. bellargus, P. coridon; Hesperiidae: Hesperia comma, Spialia sertorius; all known to still occur in dry grassland habitats in eastern Austria: Höttinger et al. 2013). In all likelihood, the magnitude of differences between management types would hence have increased under a more complete sampling scheme. The fact that the statistical power provided by of our rapid and necessarily incomplete surveys was sufficient to detect these differences suggests, however, that such "cheap surveys' may represent a useful tool for monitoring programs accomplishable even under the severe limitation of resources in many protected areas (Watson et al. 2014).

Overall, our results lend support to the hypothesis that a combination of different land-use and management options for grassland indeed provides a useful strategy to increase species diversity of butterflies and burnet moths at the landscape level. For hay harvest, earlier studies revealed that a diversification of mowing regimes may substantially contribute to biodiversity conservation (Cizek et al. 2012). Our results indicate that the parallel maintenance of mown and grazed sites in the landscape increases beta-diversity. If conservation management would, for example, only focus on the pastoral option as a method of ecological restoration, then species that reached higher densities in the other two systems might suffer from increasing local extinction risks. This could especially happen when annual population densities are low as a consequence of unusual weather conditions. To put it differently, the pluralism of management regimes with its concomitant complementarity in terms of resource conditions for organisms with a complex life cycle such as butterflies, offers a kind of insurance to maintain high species richness at the landscape level. Such a pluralism could be a particularly valuable management option for conservation areas that are sufficiently large in extent, such as the NP Neusiedlersee/Seewinkel.
Acknowledgements We thank a large number of enthusiastic students who assisted in assembling the field data underlying this study. Daniel Steinlesberger, Mislav Vulelija and Claudia Unger supported the plant data collection. We also thank John Dover, Christine Haaland, and two reviewers for their constructive suggestions. Research permits were granted by the regional government of Burgenland. This study was supported by travel funds from the Faculty of Life Sciences, University of Vienna.

Open Access This article is distributed under the terms of the Creative Commons Attribution 4.0 International License (http:// creativecommons.org/licenses/by/4.0/), which permits unrestricted use, distribution, and reproduction in any medium, provided you give appropriate credit to the original author(s) and the source, provide a link to the Creative Commons license, and indicate if changes were made.

\section{References}

Anderson M, Gorley RN, Clarke RK (2008) Permanova + for primer: Guide to software and statistical methods. Primer-E Ltd, Plymouth

Balmer O, Erhardt A (2000) Consequences of succession on extensively grazed grasslands for central European butterfly communities: rethinking conservation practices. Conserv Biol 14:746-757

Baur B, Cremene C, Groza G, Rakosy L, Schileyko AA, Baur A, Stoll P, Erhardt A (2006) Effects of abandonment of subalpine hay meadows on plant and invertebrate diversity in Transylvania, Romania. Biol Conserv 132:261-273

Berg Å, Ahrné K, Öckinger E, Svensson R, Söderström B (2011) Butterfly distribution and abundance is affected by variation in the Swedish forest-farmland landscape. Biol Conserv 144:2819-2831

Bink FA (1992) Ecologische atlas van de dagvlinders van NoordwestEuropa. Schuyt, Haarlem

Botham MS, Fernandez-Ploquin EC, Brereton T, Harrower CA, Roy DB, Heard MS (2015) Lepidoptera communities across an agricultural gradient: how important are habitat area and habitat diversity in supporting high diversity? J Insect Conserv 19:403-420

Braun-Blanquet J (1964) Pflanzensoziologie. Springer, Vienna

Bruppacher L, Pellet J, Arlettaz R, Humbert JY (2016) Simple modifications of mowing regime promote butterflies in extensively managed meadows: evidence from field-scale experiments. Biol Conserv 196:196-202

Bubová T, Vrabec V, Kulma M, Nowicki P (2015) Land management impacts on European butterflies of conservation concern: a review. J Insect Conserv 19:805-821

Catorci A, Cesaretti S, Malatesta L, Tardella FM (2014) Effects of grazing vs. mowing on the functional diversity of sub-Mediterranean productive grasslands. Appl Veget Sci 17:658-669

Cizek O, Zamecnik J, Tropek R, Kocarek P, Konvicka M (2012) Diversification of mowing regime increases arthropods diversity in species-poor cultural hay meadows. J Insect Conserv 16:215-226

Clarke KR, Somerfield PJ, Chapman MG (2006) On resemblance measures for ecological studies, including taxonomic dissimilarities and a zero-adjusted Bray-Curtis coefficient for denuded assemblages. J Exp Marine Biol Ecol 330:55-80

Crist TO, Veech JA, Gering JC, Summerville KS (2003) Partitioning species diversity across landscapes and regions: a hierarchical analysis of $\alpha, \beta$, and $\gamma$ diversity. Am Nat 162:734-743 
D'Aniello B, Stanislao I, Bonelli S, Balletto E (2011) Haying and grazing effects on the butterfly communities of two Mediterranean-area grasslands. Biodiv Conserv 20:1731-1744

Diekmann M (2003) Species indicator values as an important tool in applied plant ecology—a review. Basic Appl Ecol 4:493-506

Dover JW, Spencer S, Collins S, Hadjigeorgiou I, Rescia A (2011) Grassland butterflies and low intensity farming in Europe. J Insect Conserv 15:129-137

Dufrene M, Legendre P (1997) Species assemblages and indicator species: the need for a flexible asymmetrical approach. Ecol Monogr 67:345-366

Ellenberg H (2009) Vegetation ecology of Central Europe, 4th edn. Cambridge Univ Press, Cambridge

Ellenberg H, Weber HE, Düll R, Wirth V, Werner W, Paulissen D (1991) Zeigerwerte von Pflanzen in Mitteleuropa. Scripta Geobot 18:1-248

Fies R, Rabl D, Schulze CH, Fiedler K (2016) Summer floods shape meadow butterfly communities in a floodplain nature reserve in Central Europe. J Insect Conserv 20(3):433-445

Fischer MA, Oswald K, Adler W (2008) Exkursionsflora für Österreich, Liechtenstein und Südtirol. Biologiezentrum, Oberösterriches Landesmuseen, Linz

Höttinger H, Pendl M, Wiemers M, Pospisil A (2013) Insekten in Wien-Tagfalter. Österreichische Gesellschaft für Entomofaunistik, Wien, p. 349

Jerrentrup JS, Wrage-Mönnig N, Röver KU, Isselstein J (2014) Grazing intensity affects insect diversity via sward structure and heterogeneity in a long-term experiment. J Appl Ecol 51:968-977

Kadlec T, Tropek R, Konvicka M (2012) Timed surveys and transect walks as comparable methods for monitoring butterflies in small plots. J Insect Conserv 16:275-280

Korner I, Wrbka T, Staudinger M, Böck M (2008) Beweidungsmonitoring im Nationalpark Neusiedler See-Seewinkel. Ergebnisse der vegetationsökologischen Langzeitmonitoring-Studie 1990 bis 2007. Abh Zool-Bot Ges Österreich 37:1-84

Kruess A, Tscharntke T (2002) Contrasting responses of plant and insect diversity to variation in grazing intensity. Biol Conserv 106:293-302

Lebeau J, Wesselingh RA, Van Dyck H (2016) Floral resource limitation severely reduces butterfly survival, condition and flight activity in simplified agricultural landscapes. Oecologia 180:421-427

Lenoir L, Graae BJ, Aarrestad PA, Alsos IG, Armbruster WS, Austrheim G, Bergendorff C, Birks HJB, Bråthen KA, Brunet J, Bruun HH, Dahlberg CJ, Decocq G, Diekmann M, Dynesius M, Ejrnæs R, Grytnes J-A, Hylander K, Klanderud K, Luoto M, Milbau A, Moora M, Nygaard B, Odland A, Ravolainen VT, Reinhardt S, Sandvik SM, Høistad Schei F, Speed JDM, Tveraabak LU, Vandvik V, Velle LG, Virtanen R, Zobel M, Svenning J-C (2013) Local temperatures inferred from plant communities suggest strong spatial buffering of climate warming across Northern Europe. Global Change Biol 19:1470-1481

Loertscher M, Erhardt A, Zettel J (1995) Microdistribution of butterflies in a mosaic-like habitat: the role of nectar sources. Ecography $18: 15-26$

Marini L, Fontana P, Scotton M, Klimek S (2008) Vascular plant and Orthoptera diversity in relation to grassland management and landscape composition in the European Alps. J Appl Ecol 45:361-370

Mucina L, Grabherr G, Ellmauer T (1994) Die Pflanzengesellschaften Österreichs, vol I. Gustav Fischer, Jena
Naumann CM, Tarmann GM, Tremewan WG (1999) The Western Palaearctic Zygaenidae (Lepidoptera). Apollo Books, Stenstrup

Öckinger E, Eriksson AK, Smith HG (2006) Effects of grassland abandonment, restoration and management on butterflies and vascular plants. Biol Conserv 133:291-300

Oksanen J, Guillaume Blanchet F, Kindt R, Legendre P, Minchin PR, O'Hara RB, Simpson GL, Solymos P, Stevens MHH, Wagner H (2016) Package 'vegan'. Version 2.3-5. Available at: https:// cran.r-project.org/web/packages/vegan/vegan.pdf

Plieninger T, Hochtl F, Spek T (2006) Traditional land-use and nature conservation in European rural landscapes. Environ Sci Policy 9:317-321

Pöyry J, Lindgren S, Salminen J, Kuussaari M (2004) Restoration of butterfly and moth communities in semi-natural grasslands by cattle grazing. Ecol Appl 14:1656-1670

Pöyry J, Luoto M, Paukkunen J, Pykälä J, Raatikainen K, Kuussaari M (2006) Different responses of plants and herbivore insects to a gradient of vegetation height: an indicator of the vertebrate grazing intensity and successional age. Oikos 115:401-412

Pykälä J, Luoto M, Heikkinen RK, Kontula T (2005) Plant species richness and persistence of rare plants in abandoned semi-natural grasslands in northern Europe. Basic Appl Ecol 6:25-33

R Core Team (2014) R: a language and environment for statistical computing. R Foundation for Statistical Computing, Vienna. URL http://www.R-project.org/.

Roberts DW (2016) Package 'labdsv' Version 1.8-0. Available at: https://cran.r-project.org/web/packages/labdsv/labdsv.pdf

Rudmann-Maurer K, Weyand A, Fischer M, Stöcklin J (2008) The role of landuse and natural determinants for grassland vegetation composition in the Swiss Alps. Basic Appl Ecol 9: 94-503

Saarinen K, Jantunen J (2005) Grassland butterfly fauna under traditional animal husbandry: contrasts in diversity in mown meadows and grazed pastures. Biodiv Conserv 14:3201-3213

Schlapfer M, Zoller H, Körner C (1998) Influences of mowing and grazing on plant species composition in calcareous grassland. Bot Helv 108:57-67

Sjödin NE, Bengtsson J, Ekbom B (2008) The influence of grazing intensity and landscape composition on the diversity and abundance of flower-visiting insects. J Appl Ecol 45:763-772

Socher SA, Prati D, Boch S, Müller J, Baumbach H, Gockel S, Hemp A, Schöning I, Wells K, Buscot F, Kalko EKV, Linsenmair KE, Schulze E-D, Weisser WW, Fischer M (2013) Interacting effects of fertilization, mowing and grazing on plant species diversity of 1500 grasslands in Germany differ between regions. Basic Appl Ecol 14:126-136

Stettmer C, Bräu M, Gros P, Wanninger O (2007) Die Tagfalter Bayerns und Österreichs. 2nd ed. Akademie für Naturschutz \& Landschaftspflege, Laufen

van Swaay CA, Nowicki P, Settele J, van Strien AJ (2008) Butterfly monitoring in Europe: methods, applications and perspectives. Biodiv Conserv 17:3455-3469

van Klink R, van der Plas F, Van Noordwijk CGE, WallisDeVries MF, Olff $\mathrm{H}$ (2015) Effects of large herbivores on grassland arthropod diversity. Biol Rev 90:347-366

Watson JEM, Dudley N, Segan DB, Hockings M (2014) The performance and potential of protected areas. Nature 515:67-73

Wendelberger G (1959) Die Vegetation des Neusiedler-See-Gebietes. Sitzungsber österr Akad Wiss, Math-naturwiss Kl 168:21-41 